REMIPE

\title{
IMPORTÂNCIA DA GESTÃO ORÇAMENTÁRIA E DE CUSTOS COMO SUPORTE À TOMADA DE DECISÕES EM MICRO E PEQUENAS EMPRESAS
}

\section{IMPORTANCE OF BUDGET MANAGEMENT AND COSTS AS SUPPORT FOR DECISION MAKING IN MICRO AND SMALL ENTERPRISES}

\author{
Recebido: 28/11/2018 - Aprovado: 2/12/2019 - Publicado:02/01/2020 \\ Graciele Bergamim \\ https://orcid.org/0000-0003-0618-7112 \\ Fundação Universidade do Contestado, Campus Concórdia \\ gracielesbergamim@gmail.com \\ Emanuele Engelage \\ https://orcid.org/0000-0002-9243-5209 \\ Universidade Federal de Santa Catarina \\ manuengelage@ hotmail.com \\ Marcelo Haendchen Dutra \\ https://orcid.org/0000-0001-7640-7446 \\ Universidade Federal de Santa Catarina \\ marcelufsc45@gmail.com
} Processo de Avaliação: Double Blind Review

RESUMO: Este estudo objetiva demonstrar a importância e fomentar a utilização da gestão orçamentária e de custos em Micro e Pequenas Empresas (MPEs), ao evidenciar sua aplicabilidade e suporte à tomada de decisão em um restaurante situado no estado de Santa Catarina, Brasil. A coleta de dados ocorre entre os meses de agosto de 2017 a fevereiro de 2018. Realizam-se entrevistas e acompanhamentos dos procedimentos junto ao sócio proprietário, funcionários e membros próximos da cadeia. Também se analisam relatórios e documentos e apuram-se dados pertinentes ao mercado de atuação. Elaboramse os orçamentos operacionais da empresa (venda, matéria-prima, mão de obra, custos indiretos e custos com venda, distribuição e administração) de maio a dezembro de 2018. As informações orçamentárias são validadas pelo gestor e analisa-se sua percepção quanto à relevância do instrumento. Segundo o gestor as informações orçamentárias proporcionaram reflexão e conhecimento e o fizeram ponderar sobre a importância do planejamento e controle, incorrendo, inclusive, em mudança de algumas práticas. Isso porque, por mais que os resultados financeiros apurados sejam satisfatórios, o detalhamento das informações demonstrou que há possibilidades para maximizá-los. 
Portanto, esta ferramenta cumpre seu papel como instrumento gerencial a MPEs, ao proporcionar maior compreensão da situação atual, projetar cenários futuros e indicar pontos a serem aperfeiçoados. Apesar de reconhecer suas vantagens informacionais, o gestor apontou algumas dificuldades quanto à utilização dos orçamentos e alega que sua implantação deve ser um processo gradual.

Palavras-Chave: Orçamento Empresarial. Controle. Custos. Planejamento. Micro e Pequenas Empresas.

ABSTRACT: This study aims to demonstrate the importance and foment the utilization of the budget and cost management in a Micro and Small Enterprises (MPEs), evidencing their applicability and support to the decision making in a restaurant located in the state of Santa Catarina, Brazil. The data collection occurs between the months of August 2017 and February 2018. There are realized interviews and accompaniments of the procedures with the owner partner, employees, and close members of the chain. Also, there are analyzed reports and documents and raised the pertinent data to the actuation market. There are elaborated the company's operating budgets (sales, raw material, labor, indirect costs and costs with selling, distribution, and administration) from May to December 2018. The budgets information is validated by the manager and there are analyzed his perception about the relevance of the instrument. According to the manager, the budgets information provided reflection and knowledge and made him ponder about the importance of planning and control, incurring, even, in the changing of some practices. That is because, even though the financial results raised are satisfactory, the information detailing demonstrated that there are possibilities to maximize them. Therefore, this tool fulfills its role as a management instrument to the MPEs, by providing better comprehension of the current state, design future scenarios and indicate points to be improved. Spite acknowledging its information advantages, the manager pointed out some difficulties regarding the utilization of budgets and claims that its implementation should be a gradual process.

Keywords: Business Budget. Control. Costs. Planning. Micro and Small Business

REMIPE- Revista de Micro e Pequenas Empresas e Empreendedorismo da Fatec Osasco V. 6 Nº1 jan.-jun. 2020. 


\section{INTRODUÇÃ̃}

A economia brasileira tem como um de seus principais pilares de sustentação as Micro e Pequenas Empresas (MPEs), visto que representam cerca de 27\% do Produto Interno Bruto (PIB) nacional. Além disso, "têm um importante papel social, pois absorvem uma grande parcela da força de trabalho" (SILVA; CONCEIÇÃO; LIMA, 2013, p. 110). Segundo Koteski (2004), muitas MPEs têm tido elevadas taxas de exportações e, em função disso, recebem cada vez mais atenção dos governos. Na União Europeia, a importância das MPEs foi reconhecida pela Carta Europeia, emitida em 2000, que determinou que os governos devem aplicar esforços estratégicos para que as mesmas se desenvolvam, pois, são potenciais geradoras de empregos (LEMES; PISA, 2010). López e Hiebl (2014) também destacam a relevância das pequenas e médias empresas no desenvolvimento de economias modernas e indicam um crescente interesse da literatura contábil gerencial no tema.

Não obstante, as MPEs ainda enfrentam dificuldades para se manter no mercado. Segundo o Serviço Brasileiro de Apoio às Micro e Pequenas Empresas (SEBRAE, 2016), das empresas constituídas no Brasil em 2012, a taxa de mortalidade antes dos dois primeiros anos é de 23,4\%. Nos anos anteriores, a taxa era ainda maior (2008 - 45,8\%; 2009 - 44,6\%; 2010 - 23,80\% e 2011 - 24,2\%). Essa diminuição pode ter decorrido do aumento do PIB e de mudanças na legislação, como as alterações no Simples Nacional e a criação do Microempreendedor Individual, que fez com que muitos indivíduos que trabalhavam de forma irregular efetuassem o registro de sua empresa (SEBRAE, 2016).

Ainda assim, as taxas de mortalidade das MPEs brasileiras ainda são altas. Lemes e Pisa (2010) citam como possíveis causadores as características do mercado, a instabilidade política, a demanda versus a oferta, as estratégias definidas erroneamente, a falta de experiência pessoal e capacitação técnica, e a falta de inovação e de capacidade quanto à negociação e geração de lucro. Além disso, muitas MPEs são familiares, o que pode ocasionar problemas gerenciais derivados da falta de segregação entre pessoa física e jurídica, dos conflitos pessoais, da falta de capacitação, planejamento e controle, do poder centralizado e de decisões financeiras baseadas apenas na opinião pessoal (GERSICK; DAVIS; HAMPTON, 1997; LÓPEZ; HIEBL, 2014). 
Diante disso, torna-se importante instituir formas de planejamento e controle, para se ter práticas formalizadas que possibilitem potencializar o uso dos recursos e maximizar resultados (MÜLLER; BEUREN, 2010). Isso ocorre por meio de ferramentas de gestão, que fornecem embasamento às decisões e permitem definir estratégias assertivas. Dentre o conjunto de ferramentas gerenciais existentes, tem-se a gestão orçamentária que é um elo entre o planejamento e o controle, pois compele como uma ação para verificar se os objetivos, planos e padrões estabelecidos são seguidos. Fornece, ainda, expectativas definidas e estrutura necessária para coordenar o desempenho subsequente da organização (SCOTT; BRUCE, 1987; HORNGREN; DATAR; FOSTER, 2004).

O uso da gestão orçamentária é comum em empresas maiores, em especial as multinacionais (ISHISAKI, 2003). Apesar de as MPEs diferenciarem-se em termos de estrutura, operação e faturamento, podem utilizar muitas técnicas inicialmente desenvolvidas para empresas de maior porte, com vistas a uma gestão mais eficiente.

Muito tem se falado a respeito das limitações da gestão orçamentária para as MPEs. Zaccarelli (1996) cita como exemplos o alto custo de implantação, a falta de conhecimento por parte do empreendedor e a forma com que essa ferramenta engessa a empresa. Apesar dessa concepção se manter nos dias atuais, para Lunkes (2009), a gestão integrada de custos e de orçamentos permite detectar e eliminar desperdícios e otimizar ações para o controle de gastos, o que melhora as condições de alocações de recursos, de produtividade e, consequentemente, de lucratividade. Ainda, segundo o autor, para que seja possível orçar e controlar informações é preciso dispor de dados consistentes, verídicos e tempestivos.

Mesmo assim, grande parte das MPEs não utiliza o planejamento orçamentário e, quando o faz, geralmente, é por meio de improvisos e coleta de dados incertos (SEBRAE, 2016). Além disso, os procedimentos para suporte ao controle e gestão são pouco desenvolvidos ou nem existem e, na maioria das MPEs, os administradores são pessoas sem conhecimentos amplos sobre gestão, formados apenas na prática (SILVA et al., 2013).

Ao considerar essas limitações, os orçamentos precisam ser estruturados e adequados à realidade das empresas e de seus gestores, a fim de lhes dar suporte de forma clara e objetiva. Para Cardoso (2014), fazer um orçamento é entender a lógica do processo 
REMIPE

empresarial para atingir seus objetivos, inclusive, compreender os custos incorridos para que seja possível projetá-los de forma consistente.

Diante desse contexto, este estudo objetiva demonstrar a importância da gestão orçamentária integrada à gestão de custos como suporte à tomada de decisão em MPEs. Para tanto, define-se como objeto de análise uma microempresa localizada em Concórdia - Santa Catarina, onde se implementa as ferramentas e verifica-se se as informações geradas facilitam o planejamento e o controle financeiro e operacional. A opção por uma análise única e aprofundada torna-se uma alternativa na busca por informações que retratem a realidade empresarial, demonstrando as potencialidades orçamentárias para empresas de menor porte, mesmo com limites à generalização.

Além da contribuição literária, pois aborda sobre uma ferramenta pouco consolidada para esse tipo de empresa, este estudo foca na relevância prática. Primeiramente, as informações geradas auxiliam a empresa analisada, pois disponibilizase uma ferramenta informacional adaptada a sua realidade. Para as demais MPEs, mesmo que de outros ramos de atuação, o estudo possibilita visualizar a importância da gestão orçamentária, conscientizar sobre seus benefícios, bem como verificar sua viabilidade e indicar como implementá-la.

\section{REFERENCIAL TEÓRICO}

Este tópico visa caracterizar as MPEs e abordar a importância do planejamento e do controle para sua gestão. Também, discute sobre a gestão orçamentária, a fim de dar suporte para o desenvolvimento da pesquisa, a fim de alcançar o objetivo proposto.

\subsection{Gestão em MPEs}

Em pesquisa realizada pela Global Entrepreneurship Monitor (GEM) constatouse que o Brasil é o país com maior número de pessoas empreendedoras dentre 21 países analisados (TACHIZAWA, 2002). Dos empreendimentos formalizados, as MPEs se

REMIPE- Revista de Micro e Pequenas Empresas e Empreendedorismo da Fatec Osasco V. $6 \mathrm{~N}^{\circ} 1$ jan.-jun. 2020. 
destacam com uma representatividade de $98 \%$ nas atividades de serviços e $99 \%$ nas atividades de comércio.

O impulsionamento das MPEs foi iniciado em 1980, pelo nível de desemprego da época, onde os pequenos negócios passaram a ser considerados uma alternativa para a ocupação da mão de obra excedente. Houve, portanto, a implantação do primeiro Estatuto da Microempresa (Lei ${ }^{\circ} 7.256$, de 27 de novembro de 1984) e a sua inclusão na Constituição Federal que lhes garantiu tratamento diferenciado (IBGE, 2003).

Há diferentes definições para MPEs. A mais utilizada é a do SEBRAE (2014), que considera a quantidade de funcionários e os setores de atuação. Para o setor de serviço e comércio, as microempresas são aquelas que têm até 9 pessoas ocupadas e as pequenas têm de 10 a 49. Já na indústria, as microempresas têm até 19 e as pequenas de 20 a 99 pessoas ocupadas.

López e Hiebl (2014) afirmam que as pequenas e médias empresas requerem atenção específica quando se trata de gestão, pois possuem recursos e dificuldades distintos. Ao mesmo tempo que são mais flexíveis e adaptáveis às mudanças, devido às suas estruturas organizacionais, geralmente têm pouco acesso a recursos e são menos capazes de aproveitar as economias de escala. Isso resulta numa falta parcial ou total de competências de gestão e de contabilidade, com sistemas menos sofisticados e menos formalizados, o que também é influenciado pelo treinamento inadequado ou insuficiente da equipe e dos proprietários (LÓPEZ; HIEBL, 2014).

Essa limitação no uso de ferramentas gerenciais é confirmada por diversos autores. Ao analisar 40 MPEs dos municípios de Aracaju e Nossa Senhora do Socorro, em Sergipe, Monteiro e Barbosa (2011) indicam que as ferramentas de controladoria (planejamento, orçamento, gestão de custos, análise financeira e gestão da informação) não são utilizadas em grande escala. Além disso, indicam que há necessidade de ampliar o conhecimento sobre estratégia, controles, finanças e contabilidade gerencial, com o fim específico de se ter informações para decidir os rumos dos empreendimentos.

Santos (2001) analisou um restaurante de Brasília, que teve que ser vendido por problemas financeiros, e verificou que o empreendimento tinha uma gestão informal, pautada no conhecimento prático dos gestores, sem registros e conciliações e sem o uso de ferramentas de análises. O autor sugeriu que a realização de um plano de negócio e o

REMIPE- Revista de Micro e Pequenas Empresas e Empreendedorismo da Fatec Osasco

V. $6 \mathrm{~N}^{\circ} 1$ jan.-jun. 2020. 
uso de metodologias de controle, análise e planejamento teriam possibilitado traçar melhor as estratégias e as decisões teriam sido mais rápidas e assertivas.

Scott e Bruce (1987) também sugerem métodos e ferramentas para formulação de estratégias e para minimização de problemas em cada estágio de crescimento das MPEs. Dentre eles, os autores destacam os sistemas de controle formalizados, como os sistemas orçamentários, de custos e de informação. Sobre essas ferramentas, Ishisaki (2003) verificou que as pequenas empresas do Vale do Paraíba/SP não realizam orçamentos empresariais, pois os gestores, em sua maioria, consideram algo muito sofisticado para o segmento de negócio. Porém, conforme já mencionado, o uso da gestão orçamentária pode trazer benefícios às MPEs. Em função disso, apresenta-se a seguir uma abordagem mais detalhada sobre o tema.

\subsection{Gestão Orçamentária}

O orçamento é um instrumento que pode favorecer a otimização de resultados (PADOVEZE; TARANTO, 2011), visto que configura e determina os resultados esperados, expressando-os em termos quantitativos e representa, de maneira coordenada, as operações da empresa. Assim, com base em estimações e controles eficientes, é possível verificar os planos de curto e longo prazo, de forma a mensurar e acompanhar o progresso das ações em curso (PEREIRA; OLIVEIRA NETO, 2018).

Segundo Padoveze e Taranto (2011), a construção do orçamento deve ser feita por etapas, tornando-o um processo de gestão capaz de gerar informações adequadas. Em geral, as empresas devem passar pelas seguintes etapas orçamentárias: $1^{\circ}$ planejamento do desempenho geral da empresa e de suas subunidades; $2^{\circ}$ fornecimento de um conjunto de expectativas específicas contra o qual os resultados reais podem ser comparados (estrutura de referência); $3^{\circ}$ análise de variações em relação ao planejado, aplicando, se necessário, medidas corretivas; $4^{\circ}$ elaboração de um novo planejamento, à luz do feedback e das condições alteradas (HORNGREN et al., 2004).

$\mathrm{O}$ orçamento, em seu conceito moderno, pode ser dividido em diferentes tipos, que devem ser analisados para definir o uso de acordo com as características e a cultura da empresa (PADOVEZE; TARANTO, 2011). Para as MPEs, indica-se o orçamento empresarial, por ser capaz de se ajustar ao porte e ao tipo de atividade econômica, sendo menos complexo e engessado, além de permitir a fixação de metas, ganhos, gastos e

REMIPE- Revista de Micro e Pequenas Empresas e Empreendedorismo da Fatec Osasco

V. $6 \mathrm{~N}^{\circ} 1$ jan.-jun. 2020. 
perdas, bem como de fluxos futuros de caixa. Esse orçamento é desenvolvido de forma integrada sob todos os aspectos econômico-financeiro da organização, pois agrega diversos orçamentos setoriais, elaborados de forma sequencial (SANTOS et al., 2008).

\section{Quadro 1 - Caracterização do orçamento empresarial}

\begin{tabular}{|c|c|c|}
\hline \multicolumn{2}{|r|}{ Orçamento } & CaI \\
\hline \multicolumn{2}{|c|}{ Orçamento mestre } & $\begin{array}{l}\text { Agrega o orçamento operacional (cadeia de valores) e o financeiro (capital) } \\
\text { (BAZOLI; SANTOS, 2013) }\end{array}$ \\
\hline \multirow{6}{*}{ 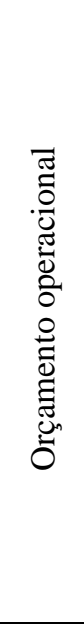 } & $\begin{array}{l}\text { Orçamento de } \\
\text { vendas }\end{array}$ & $\begin{array}{l}\text { Mensura a quantidade a ser vendida de cada item, define seus preços e prazos de } \\
\text { recebimento e calcula as receitas totais (BAZOLI; SANTOS, 2013) }\end{array}$ \\
\hline & $\begin{array}{l}\text { Orçamento de } \\
\text { produção }\end{array}$ & $\begin{array}{l}\text { Estima um nível de produção suficiente para atender a demanda prevista de vendas, } \\
\text { sem que haja estoque excessivo (LUNKES, 2009) }\end{array}$ \\
\hline & $\begin{array}{l}\text { Orçamento de } \\
\text { matéria-prima }\end{array}$ & $\begin{array}{l}\text { Estima a quantidade e as datas de compra de materi } \\
\text { com um estoque de segurança (BAZOLI; SANTOS }\end{array}$ \\
\hline & $\begin{array}{r}\text { Orçamento de } \\
\text { de obra }\end{array}$ & $\begin{array}{l}\text { cargos sociais, considerando o número } \\
\text { A, 2014) }\end{array}$ \\
\hline & $\begin{array}{c}\text { Orçamento de } \\
\text { custos indiretos de } \\
\text { produção }\end{array}$ & $\begin{array}{l}\text { Contempla custos gerais como: manutenção, energia, água, alugueis, impostos, } \\
\text { seguros, depreciação, etc. (BAZOLI; SANTOS, 2013). }\end{array}$ \\
\hline & $\begin{array}{c}\text { Orçamento de } \\
\text { vendas, distribuição } \\
\text { e administração }\end{array}$ & $\begin{array}{l}\text { Engloba gastos com a comercialização do produto, marketing, distribuição e entrega, } \\
\text { além das despesas administrativas (BAZOLI; SANTOS, 2013). }\end{array}$ \\
\hline \multirow{3}{*}{ 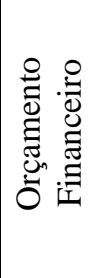 } & Orçamen & $\begin{array}{l}\text { Avalia os recursos monetários suficientes para atender às operações estabelecidas } \\
\text { nos orçamentos anteriores (LUNKES, 2009) }\end{array}$ \\
\hline & Orçamento d & $\begin{array}{l}\text { do orçado vai ser lucrativo ou não. Decorre da junção dos } \\
\text { das e de gastos (BAZOLI; SANTOS, 2013). }\end{array}$ \\
\hline & $\begin{array}{l}\text { Orçamento do } \\
\text { balanço patrimonial }\end{array}$ & $\begin{array}{l}\text { Avalia a capacidade financeira da empresa, ao apresentar seu patrimônio e se } \\
\text { desempenho financeiro (LUNKES, 2009) }\end{array}$ \\
\hline
\end{tabular}

Fonte: Elaborado pelos autores (2018)

Apesar dos orçamentos de MPEs diferenciarem-se de empresas maiores em nível de complexidade, para ambos há a necessidade de apurar os custos e conhecer suficientemente as operações, a fim de projetar dados que subsidiem fidedignamente as decisões (SOUZA, 2007). A relevância dos sistemas orçamentários e de custos também é ressaltada por Bomfim (2007), ao analisar uma MPE de Rio Grande do Sul, e por King, Clarkson e Wallace (2010), que analisaram 144 empresas da Australian Association of Practice Managers (AAPM), o que demonstra sua abrangência e proficuidade. 


\section{METODOLOGIA}

Esta pesquisa caracteriza-se como um estudo de caso, pois toma por base informações de uma microempresa da cidade de Concórdia, SC. A empresa foi fundada em maio de 2006, e atua no setor de bares, restaurantes e similares. Contém um fluxo médio de 130 pessoas servidas por dia no horário de almoço, que ocorre das 11 às 14 horas. É uma empresa familiar gerenciada pelo sócio proprietário que delibera todas as tarefas e decisões. Conta, atualmente, com sete funcionários: uma cozinheira; uma auxiliar de cozinha; duas auxiliares de serviços gerais; dois garçons e um entregador de marmitex. Os garçons e o entregador trabalham de forma intermitente, em dias alternados ou por algumas horas e são remunerados pelo período trabalhado, conforme previsto na Lei da Reforma Trabalhista (LEI n. 13.467, 2017).

A empresa não possui ferramentas de planejamento e controle, nem mesmo um sistema informacional para gerenciamento e análise de dados. A contabilidade é terceirizada e, segundo informações prévias coletadas junto ao gestor, os dados contábeis servem apenas para o cumprimento de obrigações assessórias e fiscais, não sendo utilizados gerencialmente.

Dessa forma, muitas das decisões tomadas pela empresa têm cunho emergencial e, portanto, não seguem parâmetros de estruturação e planejamento, o que condiz com os achados de Santos (2001), Monteiro e Barbosa (2011), Silva (2014) e López e Hiebl (2014). Esse fato realça a necessidade de análises que introduzam métodos e ferramentas para fundamentar as decisões, a fim de solidificar as operações e potencializar resultados.

A coleta de dados ocorreu entre os meses de agosto de 2017 a fevereiro de 2018 e, utiliza fontes primárias e secundárias. A coleta primária ocorre por meio de entrevistas e observação direta. Já a secundária, manifesta-se pela utilização de valores e informações históricas, apurados em relatórios e documentos.

As entrevistas são realizadas junto ao proprietário do estabelecimento, para obter maiores informações sobre as rotinas e particularidades do negócio. Também, realiza-se o acompanhamento dos procedimentos internos para comprovação das informações repassadas. Além do proprietário, participam da pesquisa as demais pessoas envolvidas nos processos, como funcionários e membros da cadeia de suprimentos mais próxima. Busca-se, ainda, dados relativos ao mercado de atuação, como análise de clientes,

REMIPE- Revista de Micro e Pequenas Empresas e Empreendedorismo da Fatec Osasco

V. $6 \mathrm{~N}^{\circ} 1$ jan.-jun. 2020. 
fornecedores, concorrentes e possíveis ameaças e potencialidade do mercado local. Dentre esses dados, cita-se, para fins de exemplificação, a cotação de preços, que dá base para as estimativas orçamentárias futuras e são apuradas junto ao gestor, associando sua experiência às consultas diretas.

Após coletados, os dados são organizados e analisados no software Microsoft ${ }^{\circledR}$ Excel, onde são copilados e estruturados de forma a gerar informações orçamentárias, mês a mês, para as seguintes áreas: vendas; produtividade; custos diretos (material e mão de obra); demais custos e despesas pertinentes à realização das atividades na empresa; resultados. Esses orçamentos são realizados para um período de oito meses (maio a dezembro de 2018).

Em função das demandas informacionais da empresa e dos dados disponíveis e passíveis de análise, elaboram-se apenas os orçamentos operacionais descritos no Quadro 1. Assim, como não há orçamentos financeiros, apenas um quadro resumo que indica o resultado (DRE), o orçamento mestre também não é elaborado (BAZOLI; SANTOS, 2013).

Outra delimitação é a inexistência de orçamento de produção. Isso porque, em função de sua atividade, a empresa não possui estoque, sendo que os valores estimados de venda e de produção são os mesmos. Como a refeição é estilo livre (self-service), há uma estimativa, além do consumo real, referente à margem de segurança, porém essas quantidades já são contempladas no orçamento de matéria-prima. Além disso, das etapas de elaboração do orçamento empresarial propostas por Horngren et al. (2004), este estudo direciona-se apenas às etapas 1 e 2 (estruturação), visto que não foi possível analisar as variações entre planejado e realizado (etapa 3), tampouco, remodelar o orçamento com base nas experiências passadas (etapa 4).

Após a elaboração dos orçamentos, as informações são repassadas e validadas com o proprietário. Além disso, indaga-se sobre como os dados podem auxiliá-lo nas atividades diárias e no processo de tomada de decisão, com vistas a captar sua percepção sobre à relevância do instrumento.

REMIPE- Revista de Micro e Pequenas Empresas e Empreendedorismo da Fatec Osasco V. $6 \mathrm{~N}^{\circ} 1$ jan.-jun. 2020. 
REMIPE

\section{RESULTADOS E DISCUSSÕES}

Para a realização das análises, fez-se necessária a definição de cardápios (Quadro 2), a fim de ser ter produtos específicos, com combinações padronizadas:

Quadro 2 - Cardápios para cada dia da semana

\begin{tabular}{|l|c|l|}
\hline \multicolumn{1}{|c|}{ Dia da Semana } & Cardápio & \multicolumn{1}{c|}{ Composição } \\
\hline Segunda-feira & 1 & $\begin{array}{l}\text { Arroz; Feijão; Farofa; Macarrão, Polenta; Costelinha Suína; Alface; Tomate; } \\
\text { Cenoura, Rúcula, Ovo Cozido; Vagem. }\end{array}$ \\
\hline Terça-feira & 2 & $\begin{array}{l}\text { Arroz; Feijão Carioca; Bolinho de Arroz; Macarrão à Bolonhesa; Mandioca; } \\
\text { Coxa e Sobrecoxa de Frango à milanesa; Alface; Tomate; Beterraba; Radiche; } \\
\text { Couve-Flor; Maionese de Batata. }\end{array}$ \\
\hline Quarta-feira & 3 & $\begin{array}{l}\text { Arroz; Feijão; Repolho Refogado; Macarrão Caseiro; Purê de Batata; Carne } \\
\text { Bovina em Molho; Alface; Tomate; Agrião; Rabanete; Pepino; Repolho Roxo. }\end{array}$ \\
\hline Quinta-feira & 4 & $\begin{array}{l}\text { Arroz; Feijão; Farofa; Macarrão ao Molho Branco; Nhoque; Peito de Frango } \\
\text { Grelhado; Alface; Tomate; Repolho Branco; Brócolis; Beterraba Crua Ralada; } \\
\text { Maionese de Batata. }\end{array}$ \\
\hline Sexta-feira & 5 & $\begin{array}{l}\text { Arroz; Feijoada; Farofa de Bacon; Macarrão; Batata Doce; Linguicinha } \\
\text { Assada; Bisteca Suína na Chapa; Alface; Tomate; Cebola Cozida; Cenoura } \\
\text { Crua Ralada; Couve-Folha; Feijão Branco. }\end{array}$ \\
\hline Sábado & 6 & $\begin{array}{l}\text { Arroz; Feijão; Farofa de Bacon; Macarrão; Batata-Frita; Sobrecoxa de Frango } \\
\text { Desossada Assada; Chuleta Bovina; Alface; Tomate; Ovo Cozido; Radiche; } \\
\text { Pimentão em Conserva; Maionese de Batata. }\end{array}$ \\
\hline
\end{tabular}

Fonte: Elaborado pelos autores (2018)

A empresa não possuía cardápios definidos, o que dificultava o controle de custos e muitas ações gerenciais, pois a falta de parâmetros inibia qualquer programação e gerava muitos imprevistos. Portanto, as informações do Quadro 2, além de permitirem a elaboração dos orçamentos, auxiliam na programação operacional e no contato junto aos clientes.

Dadas essas informações, elabora-se o primeiro orçamento operacional proposto no Quadro 1: o orçamento de vendas (Tabela 1), já com a totalização dos seis cardápios:

Tabela 1 - Orçamento de vendas (R\$) - total de pratos para os seis cardápios

\begin{tabular}{lrrrrrrrrr}
\hline & \multicolumn{1}{c}{ Mai. } & \multicolumn{1}{c}{ Jun. } & \multicolumn{1}{c}{ Jul. } & \multicolumn{1}{c}{ Ago. } & \multicolumn{1}{c}{ Set. } & \multicolumn{1}{c}{ Out. } & \multicolumn{1}{c}{ Nov. } & \multicolumn{1}{c}{ Dez. } & Total \\
\hline Previsão de vendas (prato) & 3.260 & 3.167 & 3.476 & 3.568 & 2.926 & 3.260 & 3.060 & 2.465 & 25.182 \\
R por unidade & 13 & 13 & 13 & 13 & 13 & 13 & 13 & 13 & 13 \\
Receita Bruta & $\mathbf{4 2 . 3 8 0}$ & $\mathbf{4 1 . 1 7 1}$ & $\mathbf{4 5 . 1 8 8}$ & $\mathbf{4 6 . 3 8 4}$ & $\mathbf{3 8 . 0 3 8}$ & $\mathbf{4 2 . 3 8 0}$ & $\mathbf{3 9 . 7 8 0}$ & $\mathbf{3 2 . 0 4 5}$ & $\mathbf{3 2 7 . 3 6 6}$ \\
Impostos $(6.84 \%)$ & 2.899 & 2.816 & 3.091 & 3.173 & 2.602 & 2.899 & 2.721 & 2.192 & 22.392 \\
Receita Líquida & $\mathbf{3 9 . 4 8 1}$ & $\mathbf{3 8 . 3 5 5}$ & $\mathbf{4 2 . 0 9 7}$ & $\mathbf{4 3 . 2 1 1}$ & $\mathbf{3 5 . 4 3 6}$ & $\mathbf{3 9 . 4 8 1}$ & $\mathbf{3 7 . 0 5 9}$ & $\mathbf{2 9 . 8 5 3}$ & $\mathbf{3 0 4 . 9 7 4}$ \\
\hline
\end{tabular}

Fonte: Elaborado pelos autores (2018)

Todas as tabelas expressam valores sem casas decimais, com arredondamentos do software Microsoft ${ }^{\circledR}$ Excel

REMIPE- Revista de Micro e Pequenas Empresas e Empreendedorismo da Fatec Osasco

V. $6 \mathrm{~N}^{\circ} 1$ jan.-jun. 2020. 
O valor de venda é o mesmo para todos os cardápios e não há previsão para atualizações nos oito meses orçados. O que se altera são as quantidades estimadas para venda, as quais consideram a média de almoços servidos nos mesmos meses do ano de 2017, atualizados por perspectivas futuras. As estimativas são feitas sob o ponto de vista do gestor, indagando-lhe sobre diferentes variáveis internas e de mercado que possam impactar nas quantidades vendidas. Também, analisa-se a quantidade de dias da semana em cada mês, já que esses determinam o cardápio servido.

Em um detalhamento dos resultados expresso na Tabela 1, tem-se que o cardápio 3 é o que tem maior previsão de saída nos oito meses (4.564 pratos), seguido do cardápio 1 (4.436) e do cardápio 4 (4.434), que possuem pouca variação entre si. A estimativa para o cardápio 2 são 4.326 pratos servidos nos oito meses e do cardápio 54.172 unidades. A menor saída é do cardápio 6, uma vez que esse é servido aos sábados, com 3.250 unidades estimadas.

Da receita bruta, são deduzidos os impostos, referentes ao Anexo I da Tabela do Simples Nacional. Para identificação da alíquota, verifica-se a média de vendas mensais, que em 12 meses, corresponde a um faturamento bruto médio enquadrado na faixa de R\$ $360.000,00$ a R\$ 540.000,00, ou seja, aplica-se uma alíquota total de 6,84\%.

Feito o orçamento de vendas, na Tabela 2, define-se o orçamento de matéria-prima (MP). O estudo não adentra em questões de estoque, estimando-se somente o necessário para cada cardápio no mês. Para o cálculo, determina-se o custo de aquisição de cada alimento por quilo ou unidade e multiplica-se pelo consumo médio de cada pessoa, apurado nos dados históricos, já considerando uma margem de segurança em função do self-service. Em seguida, aplica-se a esse valor uma taxa de atualização ao longo dos oito meses, a qual foi determinada junto ao sócio proprietário em $0,25 \% /$ mês. Dado o custo mensal de cada alimento por pessoa em cada cardápio, multiplica-se pela demanda estimada de venda, chegando-se ao custo total do alimento no mês por cardápio e, consequentemente, para os seis cardápios juntos (Tabela 2). Destaca-se que o valor dos condimentos e temperos já está incluso no custo de cada matéria-prima principal.

REMIPE- Revista de Micro e Pequenas Empresas e Empreendedorismo da Fatec Osasco V. $6 \mathrm{~N}^{\circ} 1$ jan.-jun. 2020. 
Tabela 2 - Orçamento de matéria-prima (R\$)

\begin{tabular}{|c|c|c|c|c|c|c|c|c|}
\hline & Mai. & Jun. & Jul. & Ago. & Set. & Out. & Nov. & Dez. \\
\hline$\overline{\text { Agrião }}$ & 23 & 18 & 20 & 25 & 19 & 24 & 19 & 16 \\
\hline Alface & 117 & 114 & 125 & 129 & 106 & 118 & 111 & 90 \\
\hline Arroz & 753 & 733 & 807 & 830 & 683 & 763 & 718 & 579 \\
\hline Batata Doce & 131 & 160 & 144 & 178 & 99 & 100 & 136 & 113 \\
\hline Batata-Frita & 74 & 93 & 65 & 65 & 89 & 75 & 75 & 71 \\
\hline Beterraba Cozida & 15 & 15 & 21 & 17 & 15 & 20 & 16 & 10 \\
\hline Beterraba Ralada & 19 & 15 & 17 & 21 & 15 & 16 & 16 & 13 \\
\hline Bisteca Suína na Chapa & 569 & 697 & 625 & 772 & 428 & 432 & 591 & 490 \\
\hline Bolinho de Arroz & 385 & 377 & 528 & 418 & 386 & 487 & 400 & 249 \\
\hline Brócolis & 195 & 153 & 171 & 212 & 156 & 158 & 162 & 134 \\
\hline Carne em Molho & 1.931 & 1.513 & 1.695 & 2.095 & 1.548 & 1.955 & 1.604 & 1.330 \\
\hline Cebola Cozida & 39 & 47 & 43 & 53 & 29 & 29 & 40 & 33 \\
\hline Cenoura & 15 & 15 & 21 & 17 & 15 & 20 & 16 & 13 \\
\hline Cenoura Ralada & 21 & 25 & 23 & 28 & 15 & 16 & 21 & 18 \\
\hline Chuleta Bovina & 900 & 1.128 & 796 & 789 & 1.079 & 911 & 914 & 859 \\
\hline Couve-Folha & 23 & 29 & 26 & 32 & 18 & 18 & 24 & 20 \\
\hline Costelinha Suína & 1.142 & 1.118 & 1.567 & 1.239 & 1.145 & 1.445 & 1.186 & 983 \\
\hline Couve-Flor & 389 & 381 & 534 & 423 & 390 & 493 & 404 & 252 \\
\hline Coxa e Sobrecoxa à milanesa & 406 & 397 & 557 & 440 & 407 & 513 & 421 & 262 \\
\hline Farofa & 290 & 252 & 318 & 315 & 258 & 293 & 267 & 222 \\
\hline Farofa de Bacon & 253 & 313 & 254 & 290 & 239 & 220 & 260 & 228 \\
\hline Feijão & 932 & 852 & 928 & 977 & 858 & 944 & 851 & 724 \\
\hline Feijão Branco & 155 & 190 & 170 & 210 & 117 & 118 & 161 & 134 \\
\hline Feijão carioca & 254 & 249 & 349 & 276 & 255 & 322 & 264 & 164 \\
\hline Feijoada & 421 & 516 & 462 & 571 & 317 & 320 & 437 & 363 \\
\hline Linguicinha Assada & 328 & 401 & 360 & 444 & 246 & 249 & 340 & 282 \\
\hline Macarrão & 1.715 & 1.963 & 1.948 & 1.927 & 1.660 & 1.736 & 1.770 & 1.522 \\
\hline Macarrão a Bolonhesa & 626 & 613 & 859 & 679 & 627 & 792 & 650 & 404 \\
\hline Macarrão Caseiro & 822 & 644 & 722 & 892 & 659 & 833 & 683 & 566 \\
\hline $\begin{array}{l}\text { Macarrão com Molho } \\
\text { Branco }\end{array}$ & 858 & 672 & 754 & 931 & 688 & 695 & 713 & 591 \\
\hline Maionese de Batata & 1.118 & 1.065 & 1.176 & 1.162 & 1.070 & 1.132 & 1.054 & 817 \\
\hline Mandioca & 207 & 203 & 285 & 225 & 208 & 263 & 215 & 134 \\
\hline Nhoque & 975 & 764 & 856 & 1.058 & 782 & 790 & 810 & 672 \\
\hline Ovo Cozido & 414 & 455 & 480 & 412 & 450 & 478 & 426 & 373 \\
\hline Peito de Frango Grelhado & 1.092 & 856 & 959 & 1.185 & 876 & 885 & 907 & 752 \\
\hline Pepino & 84 & 66 & 74 & 91 & 67 & 85 & 70 & 58 \\
\hline Pimentão em Conserva & 72 & 90 & 64 & 63 & 86 & 73 & 73 & 69 \\
\hline Polenta & 274 & 268 & 376 & 297 & 275 & 347 & 284 & 236 \\
\hline Purê de Batata & 366 & 286 & 321 & 397 & 293 & 370 & 304 & 252 \\
\hline Rabanete & 58 & 46 & 51 & 63 & 47 & 59 & 48 & 40 \\
\hline Radiche & 41 & 45 & 48 & 41 & 45 & 48 & 42 & 32 \\
\hline Repolho Branco & 30 & 24 & 27 & 33 & 24 & 24 & 25 & 21 \\
\hline Repolho Refogado & 111 & 87 & 97 & 120 & 89 & 112 & 92 & 76 \\
\hline Repolho Roxo & 91 & 71 & 80 & 98 & 73 & 92 & 75 & 62 \\
\hline Rúcula & 17 & 17 & 23 & 19 & 17 & 22 & 18 & 15 \\
\hline Sobrecoxa Assada & 160 & 201 & 142 & 140 & 192 & 162 & 162 & 153 \\
\hline Tomate & 815 & 794 & 873 & 899 & 739 & 825 & 777 & 627 \\
\hline Vagem & 37 & 37 & 51 & 41 & 37 & 47 & 39 & 32 \\
\hline Total & 19.765 & 19.067 & 20.892 & 21.637 & 17.936 & 19.926 & 18.695 & 15.156 \\
\hline
\end{tabular}

Fonte: Elaborado pelos autores (2018)

Nota-se que o custo médio mensal das matérias-primas para todos os cardápios é de R $\$ 19.134$, sendo que ao longo dos oito meses orçados totalizam R \$ 153.074. 
A mão de obra divide-se em mão de obra direta (MOD) e mão de obra intermitente, que corresponde aos garçons e ao entregador (custo indireto). Para o cálculo da MOD, considera-se o tempo à disposição de cada um dos quatro funcionários na empresa no ano, ponderando férias, feriados, descanso semanal remunerado e a jornada diária. Esse dado é confrontado com o custo total anual para se chegar ao custo da hora disponível de R \$27,99, já incluindo os encargos sociais (8\% de FGTS), $13^{\circ}$ salário, férias e adicional de férias. Como não há variação do tempo de trabalho entre os cardápios, calcula-se o custo dos funcionários por dia $(\mathrm{R} \$ 223,92)$ e multiplica-se pela quantidade de vezes em que cada cardápio é produzido no mês, conforme expresso na Tabela 3:

Tabela 3 - Orçamento de MOD (R\$)

\begin{tabular}{lrrrrrrrrr}
\hline & Mai. & Jun. & Jul. & Ago. & Set. & Out. & Nov. & Dez. & Total \\
\hline Cardápio 1 & 896 & 896 & 1.120 & 896 & 896 & 1.120 & 896 & 896 & 7.613 \\
Cardápio 2 & 896 & 896 & 1.120 & 896 & 896 & 1.120 & 896 & 672 & 7.389 \\
Cardápio 3 & 1.120 & 896 & 896 & 1.120 & 896 & 1.120 & 896 & 896 & 7.837 \\
Cardápio 4 & 1.120 & 896 & 896 & 1.120 & 896 & 896 & 896 & 896 & 7.613 \\
Cardápio 5 & 896 & 1.120 & 896 & 1.120 & 672 & 672 & 896 & 896 & 7.165 \\
Cardápio 6 & 896 & 1.120 & 896 & 896 & 1.120 & 896 & 896 & 1.120 & 7.837 \\
Custo total de & $\mathbf{5 . 8 2 2}$ & $\mathbf{5 . 8 2 2}$ & $\mathbf{5 . 8 2 2}$ & $\mathbf{6 . 0 4 6}$ & $\mathbf{5 . 3 7 4}$ & $\mathbf{5 . 8 2 2}$ & $\mathbf{5 . 3 7 4}$ & $\mathbf{5 . 3 7 4}$ & $\mathbf{4 5 . 4 5 3}$ \\
MOD/mês & & & & & & & &
\end{tabular}

Fonte: Fonte: Elaborado pelos autores (2018)

Após projetar os custos ligados diretamente aos produtos (MP e MOD), elaborase o orçamento dos custos indiretos (Tabela 4). Esses valores são estimados com base no mês de março de 2018, por ser o mais próximo e não ser considerado um período atípico, e aplica-se a mesma taxa de atualização utilizada para a MP.

Tabela 4 - Orçamento de custos indiretos (R\$)

\begin{tabular}{lrrrrrrrrr}
\hline & \multicolumn{1}{c}{ Mai. } & \multicolumn{1}{c}{ Jun. } & \multicolumn{1}{c}{ Jul. } & \multicolumn{1}{c}{ Ago. } & \multicolumn{1}{c}{ Set. } & \multicolumn{1}{c}{ Out. } & \multicolumn{1}{c}{ Nov. } & \multicolumn{1}{c}{ Dez. } & \multicolumn{1}{c}{ Total } \\
\hline Aluguel & 3.100 & 3.100 & 3.100 & 3.100 & 3.100 & 3.100 & 3.100 & 3.100 & 24.800 \\
Salário garçons & 676 & 676 & 676 & 702 & 624 & 676 & 624 & 624 & 5.278 \\
Salário entregador & 260 & 260 & 260 & 270 & 240 & 260 & 240 & 240 & 2.030 \\
Energia elétrica & 944 & 946 & 948 & 951 & 954 & 956 & 958 & 960 & 7.616 \\
Água & 32 & 315 & 316 & 317 & 318 & 319 & 319 & 320 & 2.539 \\
Gás & 905 & 907 & 909 & 911 & 914 & 916 & 919 & 921 & 7.300 \\
Diversos & 380 & 381 & 382 & 383 & 384 & 385 & 386 & 387 & 3.066 \\
Total & $\mathbf{6 . 5 7 9}$ & $\mathbf{6 . 5 8 5}$ & $\mathbf{6 . 5 9 1}$ & $\mathbf{6 . 6 3 4}$ & $\mathbf{6 . 5 3 2}$ & $\mathbf{6 . 6 1 1}$ & $\mathbf{6 . 5 4 5}$ & $\mathbf{6 . 5 5 2}$ & $\mathbf{5 2 . 6 2 8}$ \\
\hline
\end{tabular}

Fonte: Elaborado pelos autores (2018)

O item "diversos" contempla gastos como: guardanapo, palito de dente, marmitex, copo plástico, entre outros. A remuneração dos garçons e do entregador é por hora de 
trabalho (R \$ 6,50/hora e R \$ 5,00/hora, respectivamente), sendo que cada um atua 2 horas por dia.

O último orçamento é o de vendas, distribuição e administração (VDA). No que tange às vendas, o restaurante não incorre em gastos, visto que não há comissões, pósvenda e marketing, pois não se utiliza nenhum serviço de divulgação. Os demais custos estão descritos na Tabela 5 de forma genérica(mensal), visto que não há atribuição a cada produto (prato/cardápio):

Tabela 5 - Orçamento de vendas, distribuição e administração - VDA (R\$)

\begin{tabular}{lrr}
\hline \multicolumn{1}{c}{ Gastos } & Valor/mês & Valor total/8 meses \\
\hline Monitoramento/segurança & 100 & 800 \\
Sky & 50 & 400 \\
Materiais de escritório & 20 & 160 \\
Produtos de limpeza & 200 & 1.600 \\
Contabilidade & 250 & 2.000 \\
Despesas bancárias & 115 & 916 \\
Telefone & 55 & 440 \\
Distribuição & 240 & 1.920 \\
Pro-labore encargos sociais & 1.059 & 8.472 \\
Total & $\mathbf{2 . 0 8 9}$ & $\mathbf{1 6 . 7 0 8}$ \\
\hline
\end{tabular}

Fonte: Elaborado pelos autores (2018)

Por fim, apresenta-se um quadro resumo (Tabela 6), a fim de propiciar um melhor entendimento dos gastos totais, comparando-os com as receitas projetadas, o que permite visualizar o resultado líquido estimado ao final de cada período orçado:

REMIPE- Revista de Micro e Pequenas Empresas e Empreendedorismo da Fatec Osasco V. $6 \mathrm{~N}^{\circ} 1$ jan.-jun. 2020. 
Tabela 6 - Resultado do período orçado

\begin{tabular}{|c|c|c|c|c|c|c|c|c|c|}
\hline & Mai. & Jun. & Jul. & Ago. & Set. & Out. & Nov. & Dez. & Total \\
\hline 1. Receita líquida & 39.481 & 38.355 & 42.097 & 43.211 & 35.436 & 39.481 & 37.059 & 29.853 & 304.974 \\
\hline Cardápio 1 & 6.298 & 6.152 & 8.599 & 6.782 & 6.249 & 7.872 & 6.443 & 5.329 & 53.724 \\
\hline Cardápio 2 & 6.298 & 6.152 & 8.599 & 6.782 & 6.249 & 7.872 & 6.443 & 3.997 & 52.391 \\
\hline Cardápio 3 & 7.872 & 6.152 & 6.879 & 8.478 & 6.249 & 7.872 & 6.443 & 5.329 & 55.274 \\
\hline Cardápio 4 & 7.872 & 6.152 & 6.879 & 8.478 & 6.249 & 6.298 & 6.443 & 5.329 & 53.699 \\
\hline Cardápio 5 & 6.298 & 7.690 & 6.879 & 8.478 & 4.687 & 4.723 & 6.443 & 5.329 & 50.526 \\
\hline Cardápio 6 & 4.844 & 6.055 & 4.263 & 4.215 & 5.753 & 4.844 & 4.844 & 4.542 & 39.360 \\
\hline 2. Custo MP & 19.765 & 19.067 & 20.892 & 21.637 & 17.936 & 19.926 & 18.695 & 15.156 & 153.073 \\
\hline Cardápio 1 & 2.950 & 2.889 & 4.048 & 3.201 & 2.956 & 3.734 & 3.063 & 2.540 & 25.380 \\
\hline Cardápio 2 & 2.965 & 2.904 & 4.068 & 3.217 & .971 & 3.752 & 3.079 & 1.915 & 24.871 \\
\hline Cardápio 3 & 4.095 & 3.208 & 3.596 & 4.443 & 3.283 & 4.146 & 3.402 & 2.821 & 28.994 \\
\hline Cardápio 4 & 4.429 & 3.470 & 3.889 & 4.805 & 3.551 & 3.587 & 3.679 & 3.051 & 30.460 \\
\hline Card & 2.714 & 3.323 & 2.980 & 3.681 & 2.040 & 2.061 & 2.819 & 2.337 & 21.956 \\
\hline Car & 2.613 & 3.274 & 2.311 & 2.290 & 3.134 & 2.646 & 2.652 & 2.493 & 21.411 \\
\hline 3. Custo MOD & 5.822 & 5.822 & 5.822 & 6.045 & 5.374 & 5.822 & 5.374 & 5.374 & 45.453 \\
\hline Cardápio 1 & 896 & 896 & 1.120 & 896 & 896 & 1.120 & 896 & 896 & 7.613 \\
\hline Car & 896 & 896 & 1.120 & 896 & 896 & 1.120 & 96 & 672 & 7.389 \\
\hline Card & 1.120 & 896 & 896 & 1.120 & 896 & 1.120 & 896 & 896 & 7.837 \\
\hline Cardápio 4 & 1.120 & 896 & 896 & 1.120 & 896 & 896 & 896 & 896 & 7.613 \\
\hline & 896 & 1.120 & 896 & 1.120 & 672 & 672 & 96 & 896 & 7.165 \\
\hline & 896 & 1.120 & 896 & 896 & 1.120 & 896 & 96 & 1.120 & 7.837 \\
\hline 4. Saldo (1-2-3 & 13.895 & 13.466 & 15.384 & 15.529 & 12.126 & 13.733 & 12.991 & 9.324 & 106.448 \\
\hline Cardápio 1 & 2.452 & 2.368 & 3.431 & 2.686 & 2.397 & 3.019 & 2.484 & 1.893 & 20.730 \\
\hline & 2.437 & 2.353 & 3.411 & 2.670 & 382 & 3.000 & 2.468 & 1.410 & 20.131 \\
\hline & & & 387 & 2.915 & .070 & 2.606 & 2.145 & 1.612 & 18.443 \\
\hline Cardá & 2.324 & 1.787 & 2.094 & 2.553 & 1.803 & 1.815 & 1.868 & 1.383 & 15.626 \\
\hline Cardápio 5 & 2.688 & 3.248 & 3.004 & 3.677 & 1.975 & 1.990 & 2.728 & 2.096 & 21.405 \\
\hline Card & 1.336 & 1.662 & 1.057 & 1.029 & 1.499 & 1.303 & 1.297 & 929 & 10.112 \\
\hline 5. $\mathrm{Cu}$ & 6.579 & 6.585 & 6.591 & 6.634 & 6.532 & 6.611 & 6.545 & 6.551 & 52.628 \\
\hline 6. $\mathrm{Cl}$ & 2.088 & 2.088 & 2.088 & 2.088 & 2.088 & 2.088 & 2.088 & 2.088 & 16.708 \\
\hline 7. Resultado (4-5-6) & 5.228 & 4.793 & 6.704 & 6.807 & 3.506 & 5.034 & 4.357 & 684 & 37.112 \\
\hline
\end{tabular}

Fonte: Elaborado pelos autores (2018)

Nota-se que a empresa estima um resultado positivo para os próximos oito meses no total de $\mathrm{R} \$ 37.112$, o que, de acordo com as expectativas do sócio proprietário, é satisfatório, porém abaixo do retorno que acreditava ser possível antes conhecer e analisar detalhadamente os dados. Salienta-se que as informações supracitadas, já são validadas junto ao sócio proprietário.

Como forma de avaliar a praticidade e o suporte à tomada de decisões do instrumento elaborado, realiza-se uma nova reunião junto ao sócio proprietário para indagá-lo sobre possíveis ganhos informacionais obtidos. Com base em sua perspectiva, verifica-se que as principais vantagens se referem à apuração de dados de custos, haja vista que esses não eram mensurados em sua totalidade, tampouco segregados por produto (cardápio/prato). Ainda segundo ele, as projeções futuras expressas nos 
orçamentos, apesar de válidas e importantes para o planejamento e elaboração de estratégias, são de difícil aplicabilidade em seu cotidiano, em função do tempo demandado para elaboração.

\section{CONSIDERAÇÕES FINAIS}

O presente estudo buscou demonstrar a importância e fomentar a utilização da gestão orçamentária e de custos em micro e pequenas empresas, ao evidenciar sua aplicabilidade e suporte à tomada de decisão em um restaurante situado na cidade de Concórdia, SC. De acordo com informações repassadas pelo sócio proprietário, a elaboração dos orçamentos contribuiu para seu negócio ao trazer uma visão mais ampla e pormenorizada do que ocorre na organização. A estruturação de cardápios definidos com clareza e estipulados por dia fez com que se conseguisse mensurar com maior assertividade os custos de produção, visto que os pratos foram orçados com todos os ingredientes necessários. Ressalta-se que muitos desses custos, por serem de baixa relevância sobre o montante final, não eram devidamente apurados. Portanto, de acordo o proprietário, a maior vantagem informacional obtida foram os dados de custos apresentados de forma completa e segregados por produto (cardápio/prato).

Outro fator, que segundo o proprietário contribuiu para melhor gestão de seu negócio, é a compreensão dos custos de mão de obra sob uma perspectiva mais ampla. Isso porque, passou-se a associar à atividade os custos de $13^{\circ}$ salário, encargos sociais e férias, os quais eram tratados apenas como gastos gerais, ou seja, uma preocupação de caixa no momento em que ocorriam. Uma mudança prevista, com base nas informações do estudo, é a oportunidade de se registrar a cônjuge do proprietário como funcionária, já que a mesma não é sócia da empresa, mas atua na organização. Diante dos cálculos realizados, pode-se perceber que ao invés de realizar a contribuição para a previdência individualmente, como pessoa física, o devido registro e pagamento de encargos na empresa pode ser mais vantajoso. Esse fato reforça os argumentos de López e Hiebl (2014), de que informações devidamente apuradas podem indicar estratégias mais vantajosas. 
O proprietário também menciona a relevância do conhecimento dos gastos para a adequação dos preços de venda, pois esses, quando reajustados, consideravam apenas a variação do preço de matéria-prima. Essa perspectiva corrobora os argumentos de Gersick et al. (1997), López e Hiebl (2014) e do SEBRAE (2016), de que a falta de capacitação dos donos como administradores e a falta de planejamento e controle do negócio podem contribuir para uma gestão pouco eficiente.

Diante do exposto, pode-se perceber que a elaboração dos orçamentos proporcionou reflexão e conhecimento ao gestor, pois, por mais que os resultados financeiros apresentados sejam satisfatórios, o detalhamento das informações demonstrou que há possibilidades para maximizá-los. Assim, verifica-se que a gestão orçamentária cumpre seu papel como instrumento gerencial às MPEs.

Cabe destacar a afirmação do proprietário de que aspectos do segmento e aspectos culturais da empresa dificultam a utilização contínua do orçamento empresarial, principalmente, em função do tempo demandado para sua elaboração. Outra dificuldade mencionada é o fato de o uso desse instrumento requer informações que a empresa inicialmente não dispunha e que, mesmo com a apuração realizada para o estudo, requer controles contínuos para confrontar o orçado com o realizado. Contudo, apesar das dificuldades relatadas, o gestor reconhece os ganhos de se ter essas informações e alega que a adequação necessária para implantar controles de custos e sistemas orçamentários é um processo gradual. Assim, constata-se que, conforme mencionado por Ishisaki (2003), os gestores de pequenas empresas sabem da importância de ferramentas de gestão mas, muitas vezes, deixam de utilizá-las por acharem sofisticadas ou complicadas demais para seu negócio.

\section{REFERÊNCIAS}

BAZOLI, T. N.; SANTOS, J. L. D. Administração financeira e orçamentária. São Paulo: Pearson Education do Brasil, 2013.

BOMFIM, C. A. G. P. Planejamento financeiro e orçamento operacional em uma microempresa. Trabalho de Conclusão de Curso, Universidade Federal do Rio Grande do Sul, Porto Alegre, Brasil, 2007.

REMIPE- Revista de Micro e Pequenas Empresas e Empreendedorismo da Fatec Osasco

V. $6 \mathrm{~N}^{\circ} 1$ jan.-jun. 2020. 
REMIPE

CARDOSO, R. L. Orçamento empresarial: aprender fazendo. São Paulo: Atlas, 2014.

GERSICK, K.; DAVIS, J.; HAMPTON, M. M. De geração para geração: ciclos de vida das empresas familiares. São Paulo: Negócio, 1997.

HORNGREN, C. T.; DATAR, S. M.; FOSTER, G. Contabilidade de custos. 11. ed. São Paulo: Prentice Hall, 2004.

IBGE, Coordenação de Serviços e Comércio. As Micro e pequenas empresas comerciais e de serviço no Brasil: 2001. Rio de Janeiro: IBGE, 2003. Recuperado em 02 julho, 2017, de http://biblioteca.ibge.gov.br/visualizacao/livros/liv1898.pdf.

ISHISAKI, N. A utilização do orçamento empresarial: um estudo em empresas da região do Vale do Paraíba-SP. Dissertação de Mestrado em Administração de Empresas, Universidade de Taubaté, São Paulo, Brasil, 2003.

KING, R.; CLARKSON, P. M.; WALLACE, S. Budgeting practices and performance in small healthcare businesses. Management Accounting Research, 21(1), 40-55, 2010.

KOTESKI, M. A. As micro e pequenas empresas no contexto econômico brasileiro. Revista FAE Business, 8(1), 16-18, 2004.

LEI n. 13.467, de 13 de julho de 2017. Altera a Consolidação das Leis do Trabalho (CLT) e dá outras providências. Brasília, DF. Recuperado em 05 novembro, 2017, de http://www2.camara.leg.br/legin/fed/lei/2017/lei-13467-13-julho-2017-785204-normapl.html.

LEMES, A.; PISA, B. Administrando micro e pequenas empresas. São Paulo: Elsevier, 2010 .

LÓPEZ, O. L.; HIEBL, M. R.W. Management accounting in small and medium-sized enterprises: current knowledge and avenues for further research. Journal of Management Accounting Research, 27(1), 81-119, 2014.

LUNKES, R. J. Manual de orçamento. 2. ed. São Paulo: Atlas, 2009.

MONTEIRO, J. M.; BARBOSA, J. D. Controladoria empresarial: gestão econômica para as micro e pequenas empresas. Revista da Micro e Pequena Empresa, 5(2), 38-59, 2011.

MÜLER, E. T. C.; BEUREN, I. M. Estrutura formal e práticas da controladoria em empresas familiares brasileiras. Gestão \& Regionalidade, 26(76), 105-120, 2010.

PADOVEZE, C. L.; TARANTO, F. C. Orçamento Empresarial: novos conceitos e técnicas. São Paulo: Pearson Education do Brasil, 2011.

PEREIRA, F. I.; OLIVEIRA NETO, F. S. de (2018). As problemáticas impactantes na gestão de processos orçamentários: uma leitura de campo. Management Control Review, 2(2), 34-51, 2018.

REMIPE- Revista de Micro e Pequenas Empresas e Empreendedorismo da Fatec Osasco

V. $6 \mathrm{~N}^{\circ} 1$ jan.-jun. 2020. 
SANTOS, J. O. et al. Fundamentos de orçamento empresarial. São Paulo: Atlas, 2008.

SANTOS, V. C. O planejamento e o gerenciamento econômico-financeiros como instrumento de redução da mortalidade das micro e pequenas empresas - estudo de caso: restaurante Buongustaio. Dissertação de Mestrado em Administração Pública e de Empresas, Fundação Getúlio Vargas, Rio de Janeiro, Brasil, 2001.

SCOTT, M.; BRUCE, R. Five stages of growth in small business. Long Range Planning, 20(3), 45-52, 1987.

SEBRAE, Serviço Brasileiro de Apoio às Micro e Pequenas Empresas. Participação das micro e pequenas empresas na economia brasileira. 2014. Recuperado em 07 julho, 2017 ,

de https://m.sebrae.com.br/Sebrae/Portal\%20Sebrae/Estudos\%20e\%20Pesquisas/Participac ao $\% 20$ das $\% 20$ micro $\% 20 \mathrm{e} \% 20$ pequenas $\% 20$ empresas.pdf

SEBRAE, Serviço Brasileiro de Apoio às Micro e Pequenas Empresas. Sobrevivência das empresas no Brasil. 2016. Recuperado em 07julho, 2017, de http://www.sebrae.com.br/Sebrae/Portal\%20Sebrae/Anexos/sobrevivencia-dasempresas-no-brasil-relatorio-2016.pdf

SILVA, B.W. Controladoria empresarial: planejamento, execução e controle. BWS Consultoria, 2014.

SILVA, P. F.; CONCEIÇÃO, G. C.; LIMA, A. B. T.I. auxiliando na gestão estratégica da informação em micro e pequenas empresas. Taquaritinga: Clube dos Autores, 2013.

SOUZA, A. Gerência financeira para micro e pequenas empresas: um manual simplificado. Rio de Janeiro: Elsevier, 2007.

TACHIZAWA, T. Criação de novos negócios: gestão de micros e pequenas empresas. Editora FGV, 2002

REMIPE- Revista de Micro e Pequenas Empresas e Empreendedorismo da Fatec Osasco

V. 6 Nº1 jan.-jun. 2020. 